\title{
Conf-9107/05--55
}

UCRL-JC--105861

DE 92002656

\section{COMPARATIVE YIELD ESTIMATION VIA SHOCK HYDRODYNAMIC METHODS}

\author{
A. Attia \\ B. Moran
}

L. A. Glenn

This paper was Submitted to the Proceedings of the

American Physical Society Topical Conference on

Shock Compre;sion of Condensed Matter

Williamsburg, VA. June 17-21, 1991

June 1991

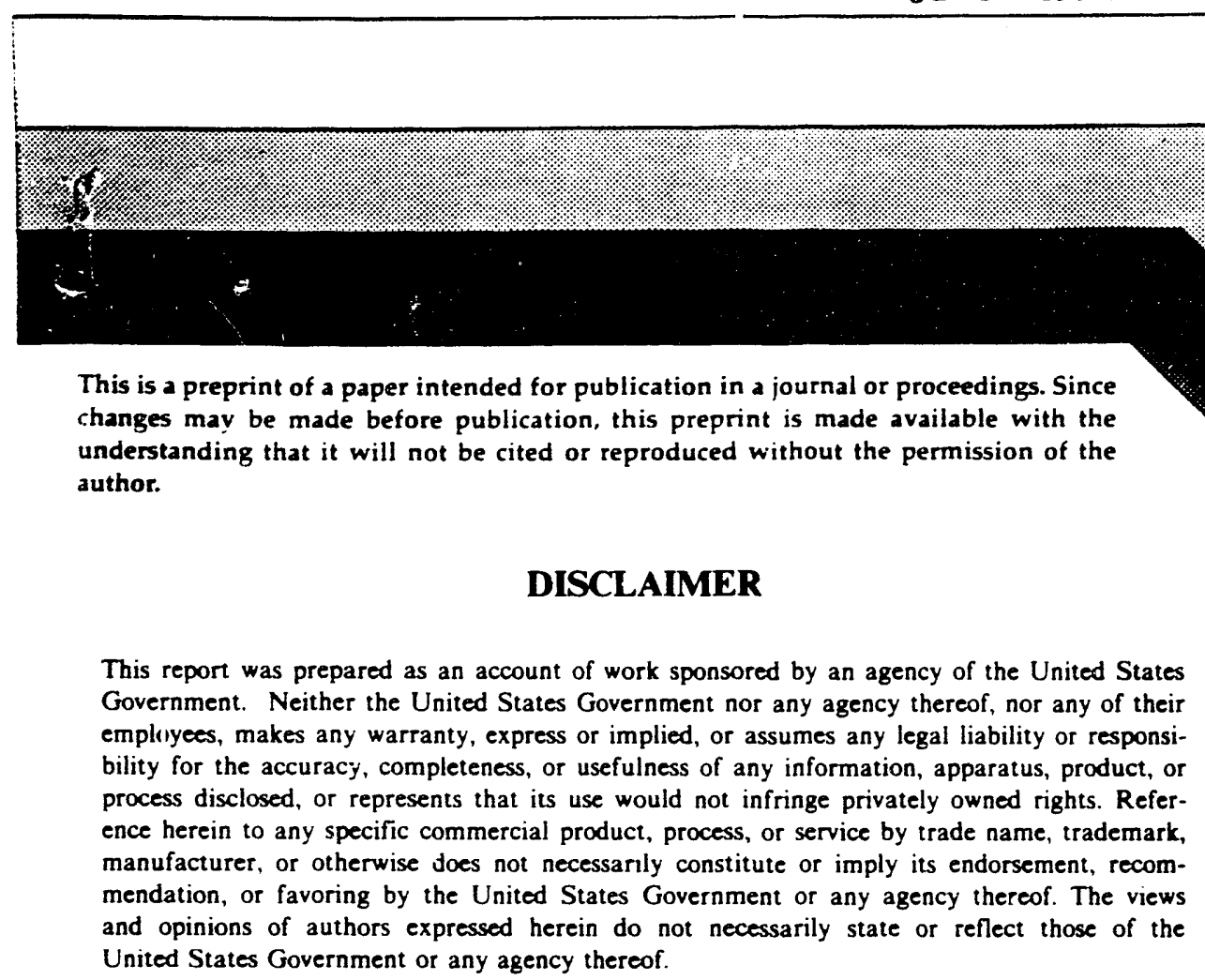

This report was prepared as an account of work sponsored by an agency of the United States Government. Neither the United States Government nor any agency thereof, nor any of their emplıyees, makes any warranty, express or implied, or assumes any legal liability or responsi, completeness, or usefulness of any information, apparatus, product, or ence herein to any specific manufacturer, or otherwise does not necessarily constitute or imply its endorsement, recomUnited States Government or any agency thereof. 


\title{
COMPARATIVE YIEID ESTIMATION VIA SHOCK HYDRODYNAMIC METHODS
}

\author{
Armand V. ATTLA, Bill MORAN, Lewis A. GLENN \\ Lawresce Livermore Napional Laboratary*
}

Shock TOA (CORRTEX) from recent underground nuciear expiosions in sanurated tuff were used to estimate yieid via the simbiated explosion-scating method. The sensinvity of the derived yieid to uncertannies in the measured shock Hugoniot. retease adiabats, and gas porosity is the main focus of this paper. In this method for determining yield, we assume a pountsource expiosion in an infinite homogeneous materal. The rock EOS is formulated using laboratory experiments on core samples. taken pior to the explosion. Resuits show that increasing gas porosity from $0 \%$ to $2 \%$ causes a $15 \%$ increase in yieid per mastais.

\section{INTRODUCTION}

The procedure for obeaining hydrodynamic yieid estimates from measured CORRTEX R-t dan has been described in detail ${ }^{1}$. We assume $t$, $L$ in a homogenous bounded materai region, an initial energy deposited. as a point source. gives rise to a spherical shock front. propagaring uniformity ourward. The towal initial energy deposited is assumed to remain in this bounded region. In Similar Explosion Scaling, measured Shock Front Range vs. Time. R(t) data. for two nuclear tests are compared for geologically simiar media. Given the known yieid in one test (the stanaard), the unkown yieid in the other test is estimated uving cube-rootscating (See Section 3, below). In Simuiared Exolosion Scaling, the standard is determmed by calculating the R(t) response of the medium. to a given yieid by modeiling the sconsunutive beinavior of the rock using shock-and-reiease experiments conducted on core sampies. The former 1.t method has the advantage of being independent of computational assumptions, but is generaily considereo less accurate whenever empiacement details and matenai properues are not exactly dupiicated. For other approaches to yieid estimation. see the works by Moss 2 and Lamo ${ }^{3}$.

We first desenibe the EOS model employed for the rocx in the simulated standard. We then show calculations that indicare the signnicant effect of shock Hugoniot, release adiabars, and gas porosity on yeid estimates obtained by scaling empiacenent-hole CORRTEX data

\section{EOS MODEZ}

The EOS was synthesized based on shock and release data obtained from plate-impact experiments on sampie cores taken from the satellite holest. Figure I shows shock Hugonio states obtained by Furnish from sampies for two events. Shock veiocity $\left(U_{s}\right)$ is plotted as a function oi partcie velocity $\left(U_{p}\right)$. The figure also shows the resuits of piecewise-linear fits to the dar. We note that for Even $Y$. data are available oniy for $U_{5}<5 \mathrm{~km} / \mathrm{s}$. At high pressure. we have chosen $U_{s}-U_{p}$ data for Event $Y$ identacal to that of Event $X$.

The Grüneisen EOS can be wntten as:

$$
P=P_{H}(1-\Gamma \mu / 2)+\Gamma \rho \varepsilon
$$

where $u=\eta-1, \eta=\rho / \rho 0$ is the comoression. $\rho$ is the density, $\rho O$ is the reierence 'non-porous/ density. $E$ is the soecinic

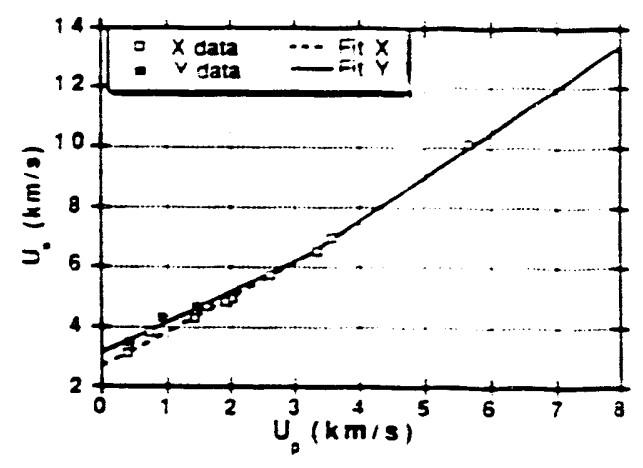

FIGLRE ! - Shock Hugoniot Data

\footnotetext{
- Work periommed under the auspices of the L.S. Deparment of Energy ov Lawrence Livermore Nauonai Laboratory under contract * W.7405-Eng-48.
} 
internal energy, and $\Gamma$ is the Grincisen coefficient. representing the racio of the thermal pressure to the thermal energy of the latrice. $P_{H}$ is the Hugoniot pressure which. with a linear $U_{5} U_{p}$ relation, reduces to:

$$
\text { - } \quad P_{H}(x)=\rho c^{2} x /(1-s x)^{2}
$$

jwhere $x \equiv \mu /(1+\mu)$, and $c=U_{g}(0)$ and $s=d U_{g} d U_{p}$.

We have chosen. for simplicity, $\Gamma=\Gamma(\rho)$ in the .CORRTEX anaiysis to date. The specific form employed for both events was developed by trial and error, using the Event $X$ emplacement-hole CORRTEX data as a basis set. Three independent inputs were also used. At normal density $(\eta=1)$, we calculated $\Gamma=0.3$ as the molar-weighted average of the known values for water and pure silica. At $\eta=2.3$, we calculated $\Gamma=0.9$ from release data + at a pressure of roughly $100 \mathrm{Gpa}$. And. for $\eta \rightarrow \infty$, we took $\Gamma=0.5$, based on Kopyshev's Thomas-Fermi calculation 5 . The final resuit was:

$$
\Gamma(\eta)= \begin{cases}0.3 & \text { if } 0 \leq \eta \leq 1: \\ -0.166+0.466 \eta & \text { if } 1<\eta \leq 2.060 \\ -3+3.218 \eta-0.668 \eta^{2} & \text { if } 2.060<\eta<2.409 \\ 0.5+1.809 / \eta-2.179 / \eta^{2} & \text { if } \eta>2.409\end{cases}
$$

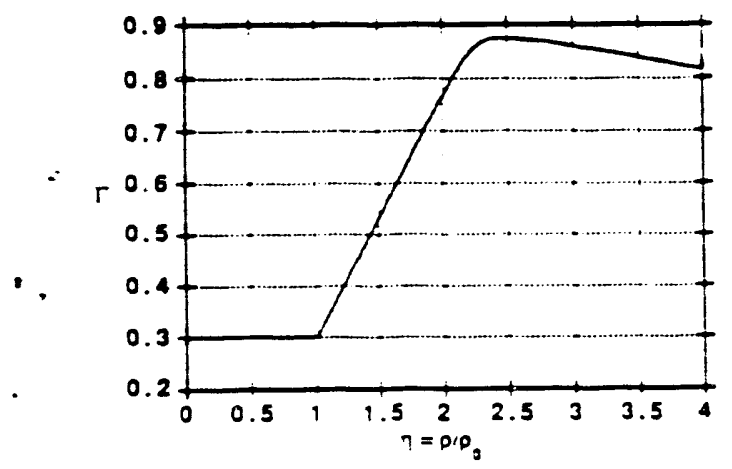

FGURE 2 - Grüneisen coetficient model

Equarion (3) is ploted in Figure 2. We note that. although the smooth transition shown for $1<\eta<2.3$ gave reasonably good agreement with experiment when porosity was introduced. this is by no means a unique sol tion. Some of the plate-impact experiments suggest that vie efiective Grineisen coefficient couid be neganve in this intervai. in particular at pressures of $7-10 \mathrm{Gpa}$. This is thought to be the resait of a Stishovite phase transition in the silica and is currenty being investigated.

The presence of gas porosity can be introduced via the Grüneisen model by assuming that the in siru density is related to the reference density, $\rho_{0}$, and porosity, $K$, by the relation:

$$
\rho(0)=(1-K) \rho_{0}
$$

For $x>0, p(0)<p_{0}$ and Equation (1) will return $P<0$ unless $\varepsilon$ is sufficienty high ; i.e.. tensile pressures will occur, in particular initially when the rock is not yet shock heated. To avoid this non-physical situation. we modify Equation ( 1 ) and set $P \equiv 0$ whenever a negative value is caiculated. This procedure is equivalent to assuming the compressive strength of the porous rock to be negigibie in comparison to the shock pressure.

\section{EFFECT OF SHOCK AND RELEASE MODEL ON YTEID ESTIMATES}

Figure 3 shows the effect of Hugoniot and Grüneisen mociels on yield esamates, when we assume no gas porosity.

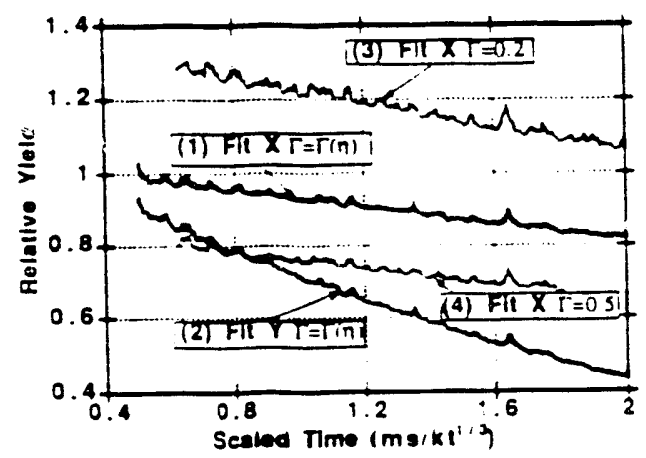

FIGURE 3 - Effect of shock-and-release mocel on yieid (Zero gas porosity)

We will first consider the effect of using Hugoniot Fits $X$ and $Y$ on the yieid estimate. with the same Grüneisen form $\Gamma(\eta)$ given by Equation (3). Resuits are shown by Curves (1) and (2) in Figure 3. To uncerstand these eff (ects on the vield esumate. we rum to the method of esumanng 
yield. Now, in cube-root-scatiog, we have, at a measured time ti and mensured shoct position $R_{i}$ :

$$
W_{\text {est }}\left(t_{i}\right)=W_{\text {sin }}\left[R_{i} / R_{\sin }\left(R_{i} / t_{i}\right)\right]^{3}
$$

where $W_{\text {sim }}$ is the yield chosen in the simulation. $W_{\operatorname{cor}}(1)$ is the estimared yield at the measured time, and $R_{\text {sim }}$ is the simulated shock position, which is evaluated at the ravio of measured position to measured time.

We now construct two Simulation Standards A and B. based on Hugonior Fits $X$ and $Y$, respectively, by performing the carresponding simuiations of the explosion. Using these no stondards, we will calculate two different yield escimates $W_{A}$ and $W_{B}$ for the single urkrown event. Let $R_{A}$ and $R_{B}$ be the shock position predicted for each measured dan point $\left(t, R_{i}\right)$ by Simulation Standards $A$ and $B$, respectiveiy. Then, using Equation (5), we have:

$$
W_{A}\left(t_{i}\right)=W_{\operatorname{sim}}\left[R_{i} / R_{A}\left(R_{i} / t_{i}\right)\right]^{3}
$$

and

$$
W_{B}\left(t_{i}\right)=W_{\text {sim }}\left[R_{i} / R_{B}\left(R_{i} / t_{i}\right)\right]^{3}
$$

Dividing Equation ( $5 \mathrm{a}$ ) by Equation ( $5 \mathrm{~b}$ ), we find that at each measured data point:

$$
W_{A} / W_{B}=\left(R_{B} / R_{A}\right)^{3}
$$

Equation (6) states that given a singie unknown event. when we use two different standards $A$ and $B$ to obtain yield estimates $W_{A}$ and $W_{B}$, we will find these estimates to be inversety proportionai to the predicted shock time histories, $R_{A}(t)$ and $R_{B}(t)$, respectively. We now appiy Equation (6) to the vields obtained by using Hugonio! Fits $X$ and $Y$. Note that from Figure 1. the Fit $Y$ Hugoniot gives a faster shock than the Fit $X$ Hugoniot. for the same paracie $\therefore$ velocity, in the lower regime $U_{p}<3 \mathrm{~km} / \mathrm{s}$. Thus. Fit $Y$ gives a more penerang shock than Fit $X$ and Equawon 10 , - . shows that Fit $Y$ produces a lower yield than Fit X. as shown by Curves (1) and (2) in Figure 3.

We next consider the effect of increasing the Grineisen coefficient $\Gamma$ from a constant value of 0.2 to 0.5 . but for the same Hugoniot (Fit $X$ ). Results are shown by Curves (3) and (4), in Figure 3. Since the shocked matenal expanas spherically outward. unioading necessarily occurs immediately behind the shock front. This unloading is controlled by the Grüneisen coetricient. The Gruneisen EOS, Equation (1), shows that an increase in $\Gamma$ resuits in reduced unioading, producing a stronger, more penetrang shock. From Equanon (6), we rind that if we increase tne
Orineisen coemctent, we wull lower the yietd escimate, as shown in Figure 3 by Curves (3) and (4).

\section{EFFECT OF GAS POROSITY ON YIELD ESTIMATES}

Figure 4 shows the effect of gas porosity on yield estimates.

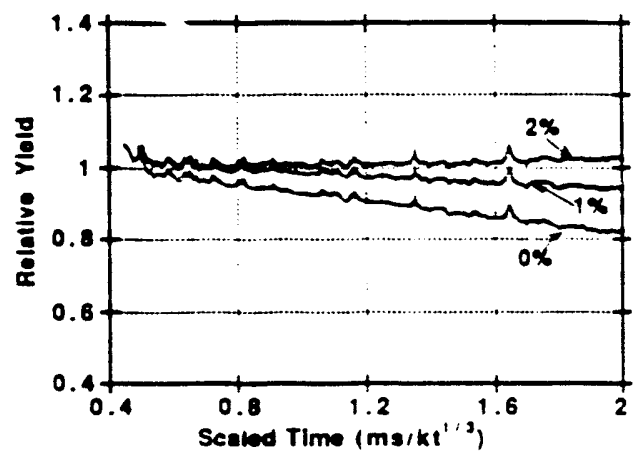

FIGURE 4 - Effect of gas porosity on neld

Using the Grineisen form in Equation (3) and the Fit $X$ Hugoniol, we now increase the gas porosity from 0 to $2 \%$. and we tind that the yieid estimates increase accordingiy. Since an increase in gas porosity causes an increase in attenuacion of the shock front. we have $K_{A}>K_{B}$ implies that $R_{A}$ $<R_{B}$ and. from $(6)$, increasing gas porosity causes an increase in vield estimate.

\section{CONCLLSIONS}

We have shown that yield esumates are very sensitive to Hugoniot, release adiabat. and gas porosity. Such sensitivity indicates the need to obtain more accurate esumates for these parameters from core samole measurements.

We found that the predicted yreld was signunicandy different when gas porosity was vaneri witnin the range: $U$ 29. Current methods for measunng gas porosity in silu are insufficient to resoive this range. and laboratory density measurements on cores otien exnibit large sampie-to-sample varations: on Event $X$. for exampie, the density variations exceeded $1.5 \%$ with cores taken trom a singie satellite hole. 
Another component of the EOS thr is not well enough defined by either theary or experimem is the effective Grincisen coefficient, $\Gamma$, which chancterives the ratio of thermil pressure of the themal energy of the lattice. It has been shown that the yield is quite sensitive 0 both $\Gamma$ and the shock Hugonior. The latter is measured adequately by plate impact experiments in the laborwory, but these experiments accurately define $\Gamma$, at best, only along the Hugoniot Away - from the Hugonior, release paths are found to lie very close or below the Hugoniot of the material, as observed by Swegle6. However. interpretarion of these release adiabats and the resuits of extracting $\Gamma$ from them are open to question because of possible metasability of the release states and rate effects during unloading. In the CORRTEX analysis that has been done to date. $\Gamma$ has accordingiy been specified only as a function of density, the specific form relying on crude thecry and a few plate-impact experiments. We are currently invesugating possible experiments which would help to establish off-Hugonio states.

\section{ACKNOWLEDGEMENTS}

We would like to acknowiedge W. Moss. J. White. and R. Heinle for helpful discussions and for reviewing this paper.

\section{REFERENCES}

1. D.S. King, B.E. Freeman, D.D. Eilers, and J.D. Johnson. The effective yield of a nuclear explosion in a small cavity in geologic material: enhanced coupling revisited. I. Geophysical Research, v. 94, n. B9 (Sept. 1989), pp. 12375-12385.

2. W.C. Moss. A method to estimate the yield of an underground nuclear explosion. Proc. of the APS Topical Conference on Shock Waves in Condensed Matter (1987), pp. 243-246.

3. F.K. Lamb, B.W. Callen, and J.D. Sullivan, An approximate analytical model of shock waves from underground nuciear explosions, submitred to Journal of Geophysical Research. December 1990.

4. M. Furnish. Dynamic properties of rocks and grouts perinent to the HYDROPLUS program. Sandia National Laboratory Reporr. 1991 (in press).

5. V.P. Kopyshev. Grüneisen constant in the ThomasFermi approximation. Sov. Phys. Dokladv, v. 10. n. 4 (Oct. 1965), pp. 338-339.

6. J.W. Swegle, Irreversible phase transitions and wave propagation in silicate geologic materials. Proc. of the APS Topical Conference on Shock Compression of Condensed Matter (1989) pp. 147-150 

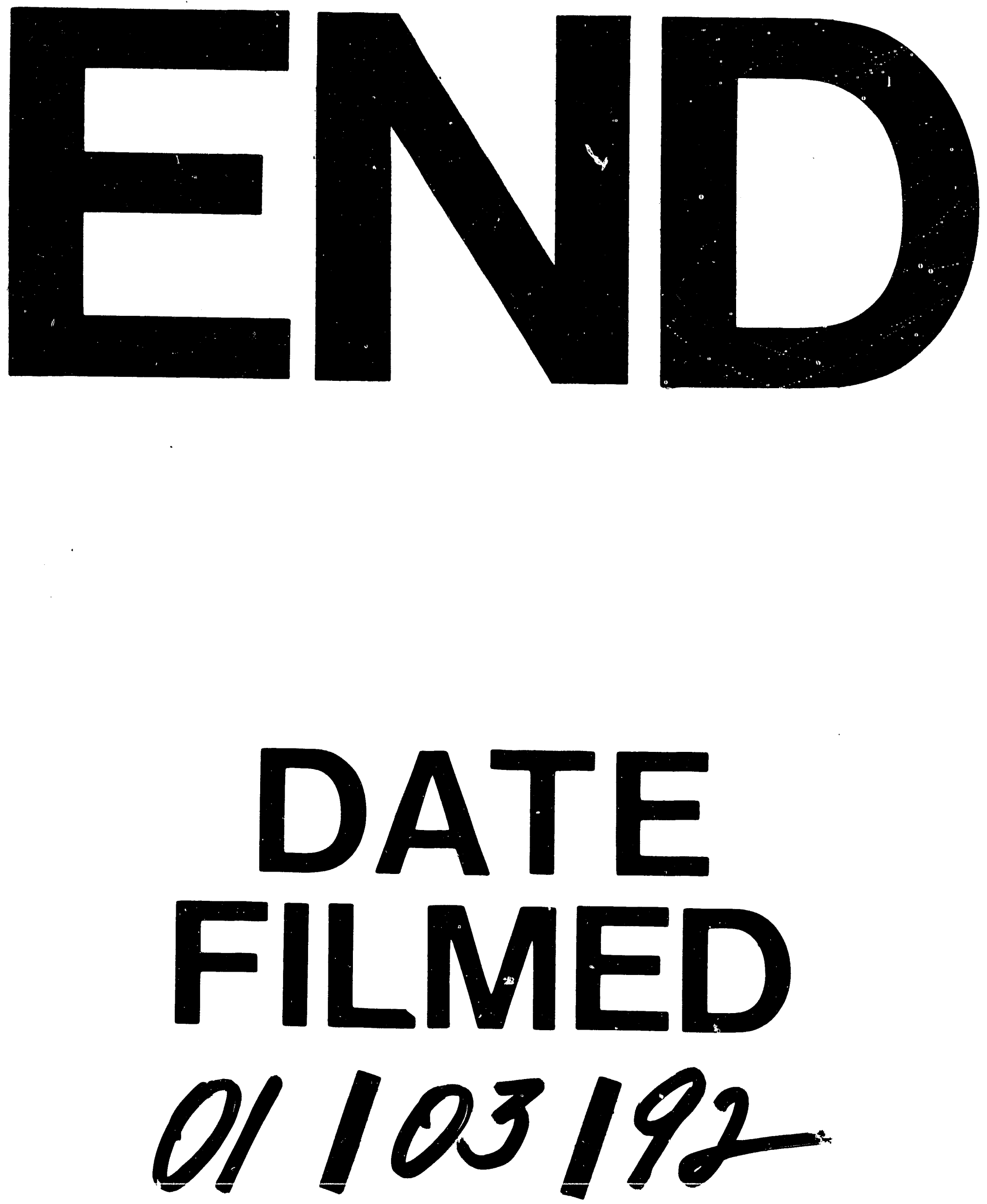
